ИЗВЕСТИЯ АКАДЕМИИ НАУК ЭСТОНСКОИ ССР. ТОМ 26 ХИмИЯ * ГЕОЛОГИЯ. 1977 , № 4

\title{
ИССЛЕДОВАНИЯ ПРЕВРАЩЕНИЯ -ПЕНТАНА В ВЧ-ТЛЕЮЩЕМ РАЗРЯДЕ
}

J. KAUP, K. TAJUR, O. EISEN. n-PENTAANI MUUNDUMISEST HUUMLAHENDUSES

J. KAUP, K. TAJUR, O. EISEN. ON THE DECOMPOSITION OF $n$-PENTANE IN GLOW DISCHARGE

Превращения разных химических соединений в электрических разрядах исследовались многими учеными $\left[{ }^{1-7}\right]$. Из алифатических углеводородов наиболее детально изучен метан в различных условиях и разрядах $\left.{ }^{8-14}\right]$. Превращения этана, этилена, ацетилена, а в особенности выс-

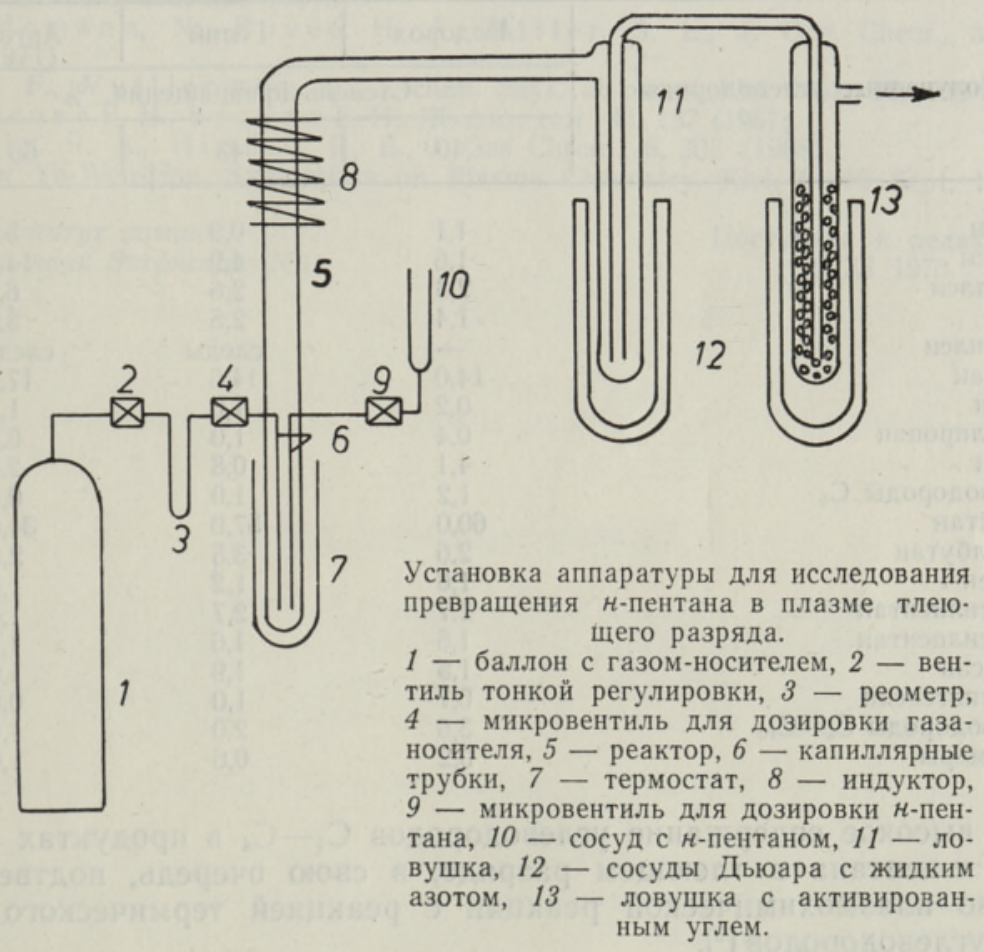

ших алифатических углеводородов в электрических разрядах изучены сравнительно мало. В литературе отсутствуют данные о превращениях алифатических углеводородов $\mathrm{C}_{5}-\mathrm{C}_{7}$ в плазме тлеющего разряда. 
В настоящей работе изложены результаты изучения превращения $\boldsymbol{H}$-пентана в плазме ВЧ-тлеющего разряда.

Использованная в наших опытах аппаратура (рисунок) была аналогичной аппаратуре, описанной в $[5,7,13]$. Рабочая частота высокочастотного генератора $13,56 \mathrm{Mzц}$ позволила использовать безэлектродный реактор. Энергия вводилась с помощью индуктора, состоящего из 6-миллиметровой медной трубки (11 витков). Опыты проводились в стеклянной (из пирекса) аппаратуре проточного типа. Газами-носителями служили водород, гелий и аргон. Скорость подачи н-пентана 0,1 мл/мuн. Продукты реакции конденсировали в ловушках, охлаждаемых жидким азотом. Реактор в индукторе охлаждали снаружи вентилятором. Объем разрядной зоны - 10 мл.

Опыты проводились при остаточном давлении 3 мм рт. ст. Продукты превращения н-пентана в плазме тлеющего разряда анализировались методом газожидкостной хроматографии. В качестве жидкой фазы служил сквалан. Состав углеводородов $\mathrm{C}_{1}-\mathrm{C}_{4}$ уточняли на полисорбе- 1 . Индивидуальные компоненты идентифицировались по временам удерживания и путем сравнения с эталонными углеводородами.

Установлено $\left[{ }^{5,7}\right]$, что электрические разряды обусловливают возбуждение, ионизацию и разложение органических веществ, а также синтез новых молекул. Как и следовало ожидать, в плазме тлеющего разряда из $\boldsymbol{H}$-пентана образовались предельные и непредельные углеводороды с числом атомов углерода в них меньше и больше пяти (таблица). Относи-

Продукты превращения $\boldsymbol{\mu}$-пентана в ВЧ-тлеющем разряде

\begin{tabular}{|c|c|c|c|}
\hline \multirow{3}{*}{ Полученные углеводороды } & Водород & Гелий & Аргон \\
\hline & \multicolumn{3}{|c|}{ Степень превращения, \% } \\
\hline & 40 & 43 & 66 \\
\hline $\begin{array}{l}\text { Метан } \\
\text { Этилен } \\
\text { Ацетилен } \\
\text { Этан } \\
\text { Пропилен } \\
\text { Пропан } \\
\text { Аллен } \\
\text { Метилпропан } \\
\text { Бутан } \\
\text { Углеводороды } \mathrm{C}_{4} \\
\text { н-Пентан } \\
\text { Метилбутан } \\
\text { Пентен-1 } \\
\text { 2-Метилпентан } \\
\text { 3-Метилпентан } \\
\text { н-Гексан } \\
\text { 3-Метилгексан } \\
\text { Углеводороды } \mathrm{C}_{6}-\mathrm{C}_{10} \\
\text { Полимеры }\end{array}$ & $\begin{array}{r}1,1 \\
1,6 \\
2,3 \\
1,4 \\
14,0 \\
14,2 \\
0,4 \\
4,1 \\
1,2 \\
60,0 \\
2,6 \\
1,0 \\
2,7 \\
1,5 \\
1,5 \\
0,7 \\
3,6 \\
0,2\end{array}$ & $\begin{array}{c}0,9 \\
4,9 \\
2,6 \\
2,5 \\
\text { следы } \\
14,6 \\
1,0 \\
1,0 \\
0,8 \\
1,0 \\
57,0 \\
3,5 \\
1,2 \\
2,7 \\
1,6 \\
1,9 \\
1,0 \\
2,0 \\
0,6\end{array}$ & $\begin{array}{r}5,7 \\
14,0 \\
6,5 \\
5,0 \\
\text { следы } \\
17,5 \\
1,7 \\
0,7 \\
2,0 \\
0,8 \\
34,0 \\
2,0 \\
1,8 \\
1,4 \\
1,1 \\
1,9 \\
0,8 \\
1,4 \\
1,6\end{array}$ \\
\hline
\end{tabular}

тельно высокое содержание углеводородов $\mathrm{C}_{1}-\mathrm{C}_{4}$ в продуктах превращения $\boldsymbol{H}$-пентана в тлеющем разряде, в свою очередь, подтверждает сходство плазмохимической реакции с реакцией термического разложения углеводородов [ $\left.{ }^{5}\right]$.

Интересно отметить, что природа газа-носителя оказывает существенное влияние на глубину процесса, т. е. на степень превращения $\boldsymbol{H}$-пентана, а также на количество углеводородов с числом атомов угле- 
рода в них меньше пяти. Как следует из полученных данных, содержание пропана в продуктах реакции в присутствии водорода и гелия в несколько раз выше содержания углеводородов $\mathrm{C}_{1}-\mathrm{C}_{2}$, а в присутствии аргона сходно с содержанием этилена. Это обстоятельство показывает, что, по всей вероятности, разрыв углеродной цепи $\mathrm{C}_{5}$ происходит между вторым и третьим атомами углерода $н$-пентана.

Следует отметить, что, кроме образовавшихся жидких продуктов превращения н-пентана в плазме ВЧ-тлеющего разряда, на стенках реактора появлялась пленка из твердых полимеров. Аналогичные результаты получены и при превращении дах $\left.{ }^{15}\right]$.

\section{Л И Т Е Р А Т У Р А}

1. Thomas, C. L., Egloff, G., Morel1, J. C., Chem. Rev., 28, 43 (1941).

2. McTa g g a rt, F. K., Plasmachemistry in Electrical Discharges. Elsevier, Amsterdam, 1967.

3. B a ddour, R. F., Timmins, R. S., The Application of Plasma to Chemical Processing. Pergamon, Oxford, 1967.

4. Su h r, H., Angew. Chemie, 84, 876 (1972).

5. Suhr, H., Rolle, G., Shrader, B., Naturwissenschaiten 55, 168 (1968).

6. Suhr, H., Topics in Current Chemistry, Synthesis of Organic Compounds in Glow and Corona Discharges. Springer-Verlag, Berlin, Heidelberg, New York, 1973.

7. Кинетика и термодинамика химических реакций в низкотемпературной плазме. М., 1965.

8. Химические реакции органических продуктов в электрических разрядах. М., 1966.

9. Бе б е ш к о Г. И., Е р е м и н Е. Н., Ж. фнз. хим., 48, 609 (1974).

10. Capezzuto, P., Francesco, C., Pasquale, M., Ettore, M., Cazz. Chim. ital., 103, 891 (1973).

11. Friedemann, N., Bovee, H. A., Miller, S. L., J. Org. Chem., 36, 2894 (1971).

12. Goff, F., Vuillermos, B., J. chim. phys. et phys. chim. biol., 66, 403 (1969).

13. Бо р и со в а Е. Н., Е ре ем и н Е. Н., Ж. физ. хим., 41, 137 (1967).

14. Hively, R. A., Hi nton, R. E., J. Gas Chrom., 6, 203 (1968).

15. Pedrow Yii-Wen-Hsu, Symposium on Plasma Chemistry, Kiel, 6-10 Sept. 1973. 